\title{
Carlos Nelson Coutinho
}

\author{
José Paulo Netto*
}

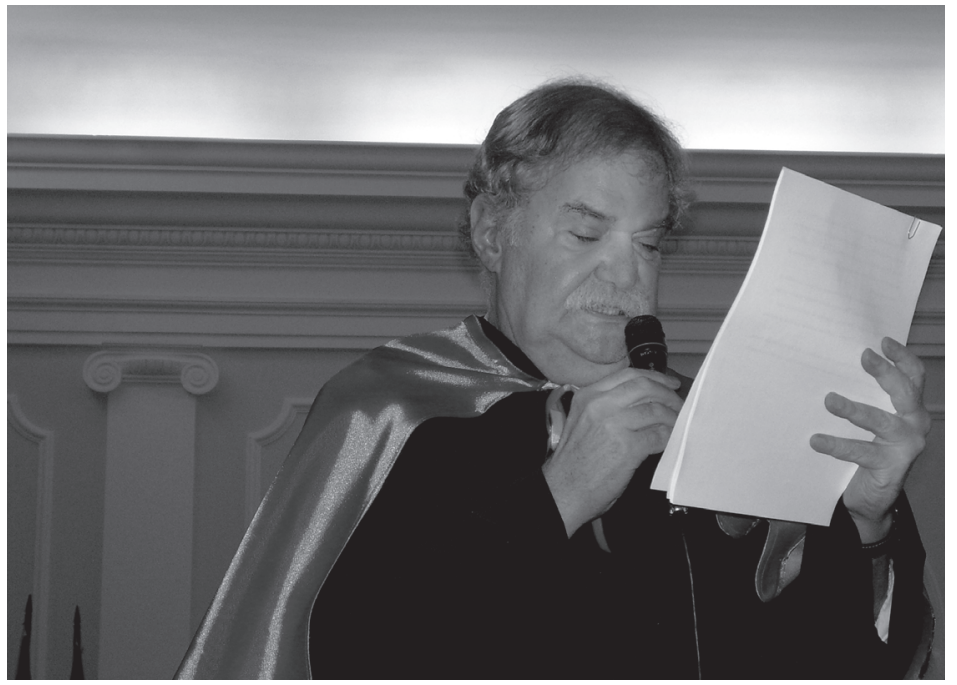

Em meados de 1967, saía pela Editora Paz e Terra, do Rio de Janeiro, um volume de ensaios - Literatura e humanismo - cujo autor era um baiano de 24 anos. O livro afirmava, imperativamente, o talento crítico (que o jovem já revelava, ainda como precoce promessa, nos ensaios que vinha publicando em importantes jornais e revistas desde os 17 anos) do autor em dois níveis: de uma parte, a sua rigorosa referência teórica; de outra, a sua criatividade na implementação das matrizes que orientavam o seu pensamento.

É que, no conjunto dos textos ali reunidos, havia não só a pioneira explicitação dos parâmetros analíticos da teoria do realismo de Lukács, mas a sua aplicação criadora a um clássico da literatura brasileira - e os dois ensaios respectivos (um sobre o realismo como categoria central da estética e outro sobre o romance de Graciliano Ramos) tornaram-se, desde então, antológicos. Com Literatura e humanismo, seu autor, Carlos Nelson Coutinho, inseriu-se entre os críticos literários brasileiros mais qualificados.

* Professor Emérito da Universidade Federal do Rio de Janeiro (UFRJ). 


\section{paVistra pll palltg}

Favoreceu-o, nesta inserção, tanto a sua formação teórica (na universidade, graduou-se em Filosofia) quanto as suas escolhas literárias (sempre vinculadas a autores clássicos da literatura universal). No prosseguimento da sua atividade crítica, tornou-se - juntamente com Leandro Konder, numa parceria que se iniciou nos anos 1960 e continua até hoje - um interlocutor de György Lukács e produziu mais alguns ensaios que haveriam de ser consagrados (entre outros, sobre Lima Barreto, Marcel Proust e Franz Kafka).

O segundo livro de Carlos Nelson - publicado em 1972 e logo traduzido no México -, O estruturalismo e a miséria da razão, mantém a sua estrita fidelidade ao pensamento de Lukács, mas expressa, também e novamente, a criatividade do autor: se o filósofo húngaro já analisara a "destruição da razão", Carlos Nelson lança luz sobre o processo de constituição da "razão miserável" (de que o estruturalismo francês dos anos 1960 era emblemático), que não fora objeto da pesquisa de Lukács. A relevância deste livro, que o autor tardou quase quarenta anos a reeditar, foi atestada recentemente pelo público leitor: a segunda edição (2010) esgotou-se em menos de um ano.

A trajetória intelectual de Carlos Nelson experimenta uma inflexão na segunda metade dos anos 1970. Obrigado ao exílio pela ditadura, viveu, entre inícios de 1976 e o fim de 1978, na Europa (Itália, Portugal, França) - quando pôde tornar-se explicitamente um protagonista da luta política, uma vez que, no Brasil, desde 1964, sua intervenção na resistência democrática, como membro do PCB, tivera que ser obrigatoriamente encoberta. Na Europa, estuda intensivamente os clássicos da teoria política, especialmente Gramsci - de que fora o tradutor já em 1966 - e participa da luta interna travada no PCB (do qual se afastará em 1981).

O Carlos Nelson que regressa ao país na agonia da ditadura tem, agora, um interesse especial pela política, na teoria e na prática. E logo no seu retorno publica um ensaio de enorme repercussão: "A democracia como valor universal" (1979). Este texto marca o deslocamento de seus objetos de reflexão e pesquisa: sem abandonar o ofício de tradutor e a crítica literária e cultural, agora o seu esforço dirigese mais para a teoria e a prática políticas.

Nesta seara, porém, o seu objetivo prioritário passou a ser a compreensão do Brasil. A partir de então, se produz textos sobre questões teóricas do movimento socialista, o que elabora essencialmente é uma série de ensaios esclarecedores acerca do nosso país, seja sobre analistas da história brasileira (como o seu estudo antológico de Caio Prado Jr.), seja sobre problemas candentes da nossa sociedade (como os referidos à nossa "via prussiana", à relação Estado/sociedade civil e à questão democrática). Na segunda metade dos anos 1980, engrossa com entusiasmo as fileiras do PT - recorde-se que fez parte, na entrada dos anos 1990, do "governo paralelo" deste partido, do qual se afastaria posteriormente para participar do processo de fundação do P-SOL.

Mas o retorno do exílio também marcou um giro profissional na trajetória de Carlos Nelson. Até então avesso à vida acadêmica, ele começa por lecionar no ensino superior privado e depois ingressa (por concurso público de livre-docência, em 1987) na Escola de Serviço Social da Universidade Federal do Rio de Janeiro (ESS/UFRJ), à qual passa a servir em regime de dedicação exclusiva e tempo integral 


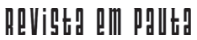

até sua aposentadoria (no presente ano). Nesta unidade acadêmica, sua competência e sua generosidade granjearam-lhe o respeito de seus pares e a admiração de seus alunos, dezenas dos quais orientou em nível de mestrado e doutorado.

Cabe aqui uma notação rápida e específica. Na ESS/UFRJ, Carlos Nelson jamais se acomodou na posição de um "estranho no ninho", recusou-se sempre a ser um mero observador externo do/ao Serviço Social. De fato, interessou-se pelos debates do Serviço Social, leu os principais autores da sua bibliografia, prestigiou os eventos da categoria profissional e ofereceu a sua contribuição a encontros e seminários de pesquisa. Converteu-se, nas suas próprias palavras, em um "assistente social honorário".

No exercício docente, seu prestígio acadêmico (obviamente conectado à sua condição de ensaísta brilhante) logo ganhou ressonância nacional, atestada pelos convites que o levaram a participar de seminários, colóquios e bancas de concurso e de dissertações e teses nas universidades brasileiras mais importantes.

A partir de meados dos anos 1990, o trabalho intelectual de Carlos Nelson começa a repercutir para além das fronteiras do Brasil - num processo que, na primeira década deste século, fará dele um pensador internacionalmente conhecido. Pronuncia conferências na Argentina, no México e na Itália. Livros seus são publicados na Itália, em Cuba e no Chile e seus textos são traduzidos ao inglês, ao italiano, ao francês, ao castelhano e até ao japonês e ao romeno.

Neste período, prossegue redigindo ensaios, publicando livros, intervindo na imprensa, concedendo entrevistas a periódicos brasileiros e estrangeiros - porém, o projeto a que se dedica intensivamente é a edição em português, em seis volumes, dos gramscianos Cadernos do cárcere (ademais de dois volumes das Cartas do cárcere e outros dois de Escritos políticos). À realização deste projeto (1999-2005), contando com a colaboração de Marco Aurélio Nogueira e Luís Sérgio Henriques, Carlos Nelson conferiu tal qualidade e erudição que esta versão brasileira de Gramsci é considerada, entre todas as traduzidas do italiano, a mais credibilizada. Assim, não foi por acaso que Carlos Nelson tornou-se uma referência na direção da International Gramsci Society.

Levando-se em conta a sua produção intelectual registrada, é fora de dúvida que ela deve ser avaliada como substantiva - Carlos Nelson é a concreta negação do preconceito segundo o qual os baianos são pouco afeitos ao trabalho. ${ }^{1}$ Mas a substantividade aqui referida nada tem a ver com a dimensão quantitativa: tem

${ }^{1}$ Com efeito, a capacidade de trabalho intelectual de Carlos Nelson é ímpar. Para além da sua atividade política e, nos últimos 25 anos, do seu exercício docente, empreendeu a tradução de mais de 60 livros, escreveu 41 ensaios como capítulos de livros e 67 como artigos em revistas de crítica literária e periódicos acadêmicos e políticos e publicou 13 livros: Literatura e humanismo. Ensaios de crítica marxista, 1967; O estruturalismo e a miséria da razão, 1972; A democracia como valor universal. Notas sobre a questão democrática no Brasil, 1980 (2ª ed. ampliada: A democracia como valor universal e outros ensaios, 1984); Gramsci, 1981; A dualidade de poderes. Introdução à teoria marxista de Estado e revolução, 1985 (2ª ed. ampliada, 1987); Gramsci. Um estudo sobre seu pensamento político, 1989 (2a ed. revista e ampliada, 1999); Cultura e sociedade no Brasil. Ensaios sobre idéias e formas, 1990 (4a edição revista e ampliada, 2011); Democracia e socialismo. Questões de princípio \& contexto brasileiro, 1992; Marxismo e política, 1994; Contra a corrente. Ensaios sobre socialismo e democracia, $2000\left(2^{2}\right.$ ed. revista e atualizada, 2008); Lukács, Proust e Kafka. Literatura e sociedade no século XX, 2005; Intervenções. O marxismo na batalha das idéias, 2006; De Rousseau a Gramsci. Ensaios de teoria política, 2011. Ademais, foi o organizador (ou co-organizador) de várias antologias de, entre outros, Lukács e Gramsci, e ainda exerceu, entre 2004 e 2011, a Direção da Editora UFRJ. 


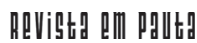

tudo a ver com uma obra que marca profundamente a cultura brasileira no seu sentido mais amplo e nela se inscreve duradouramente.

Trata-se de uma obra em que a crítica literária, cultural e social dá as mãos à elaboração teórica e política e à intervenção sociocêntrica. Obra que, diferenciada no curso de sua constituição, tem o seu fundamento numa rigorosa e criativa exegese de Marx, Lukács e Gramsci e se desenvolve numa unidade garantida, entre outros componentes, pela sempre reafirmada opção revolucionária de Carlos Nelson. Obra que, como poucas produzidas por pensadores da sua geração, confere a ele um relevo notável entre todos os seus contemporâneos.

Por isto mesmo, esta homenagem de vida é tão justificada quanto o são as outras várias homenagens em vida prestadas a Carlos Nelson nestes últimos dias de junho de 2012, quando, a 28, ele completou 69 anos e, a 29, em nome do Conselho Universitário, o Magnífico Reitor da Universidade Federal do Rio de Janeiro presidiu a cerimônia solene em que se Ihe atribuiu o título de Professor Emérito. Emérito entre eméritos, receberá ainda, a 3 de julho, o preito de agradecimento da comunidade acadêmica da ESS/UFRJ.

E são mesmo homenagens de vida e em vida, porque Carlos Nelson Coutinho ainda tem muito a fazer e a dizer - os mais próximos estão a cobrar-lhe a sua Breve história da filosofia (título provisório), que não avançou além do século XVIII. Mas, também, porque os seus amigos e camaradas estão longe de considerar que, apesar de tanto e tão profícuo trabalho, ele já possa desfrutar de um merecido otium cum dignitate - isto, nós só lhe concederemos quando ele ficar velho.

Recebido para publicação em 29 de junho de 2012. 